\title{
Daily Variation of the Iodine Number of Human Milk Fat and Influence of Vitamin $B_{1}$ on the Iodine Number and Arakawa's Reaction.
}

181st Report of the Peroxidase Reaction. (128th Human Milk Study.)

By

\author{
Yadori Moriwaki. \\ (森 脇 若)
}

From the Department of Pediatrics, Faculty of Medicine, the Tohoku Imperial University, Sendai.

Director: Prof. A. Sato,

In a preceding paper of mine ${ }^{1)}$ (Cf. 180th Report of the Peroxidase Reaction), I made an investigation into the relation between the quality of milk fat and Arakaw a's reaction of human milk, and found that the iodine number of milk fat was high in the milk of Arakawa-negative mothers and was low in that of Arakawa-positive ones*. In other words, the fat of Arakawa-negative milk was more unsaturated than that of Arakawa-positive milk. And as has been shown repeatedly in a number of papers from our aboratory (Cf. Reports of the Peroxidase Reaction), Arakawa-negative milk is buman milk from a $B_{1}$-avitaminotic body. The iodine number of milk fat is thus higher in the case of $B_{1^{-a v i t a m i n o t i c}}$ mothers than in the case of healthy (non $\mathrm{B}_{1}$ avitaminotic) mothers. From this result one can easily presume that the iodine number of milk fat in Arakawa-negative milk will decrease on an administration of vitamin $\mathrm{B} f$ to the nursing mother.

1) Y. Moriwaki, Tohoku J. Exp. Med., 1944, 47, 348.

* Arakawa-positive may be used in two different senses. One of these is: Arakawa-positive in a biochemical sense. A sample of human milk is said to have become Arakawa-positive, when it becomes blue on the addition of A rakawa's reagent. Here it means that the sample is not negative to A rakawa's reaction. The other of these two sense is: Arakawa-positive in a clinical sense. A sample of human milk is clinically Arakawa-positive only when it shows such a reaction as $\mathrm{tt}$ or $\mathrm{ft}$ in one minute of the addition of $\mathrm{Arakawa}$ 's reagent. Another sample of human milk may be Arakawa-positive in the first described sense, but yet clinically negative.

$t$ Vitamin $B_{1}$ is meant throught the article. 
In the present paper, the following problems were studied.

1. Daily variation of the iodine number of milk fat (without an administration of vitamin $B_{1}$ ) and the variation of iodine number in menstrual period.

2. Influence of vitamin $B_{1}$ on the iodine number of milk fat in both Arakawa-positive and -negative milk.

3. Animal experiment (preliminary report).

\section{Method and Materials.}

1. Method of the iodine number determination: My own micro method with 1.0 c.c. of human milk which is described in a preceding paper ${ }^{2)}$ (Cf. 28th Report on Micro Method).

2. Materials : Milk samples were taken from mothers of sick infants who visited our Dispensary, or who were admitted to our Department.

As to the amount of vitamin B administered to mothers and as to the method of animal experiment, see later.

\section{Result of Experiment.}

1. Daily variation of the iodine number of buman milk fat (witbout administration of vitamin $B_{1}$ to mothers).

Case No. 1 (Cf. Table 1). As is seen from Table 1, Arakawa's reaction of milk in this case was very strong on the right side of the breast, and the milk of the left side was generally of rather stronger A rakawa's reaction, though there were fluctuations during the whole course of experiment. The iodine number of milk fat was almost onstant showing only a slight fluctuation.

\section{TABle I.}

Case No. 1. T.A., male, aged 10 months. Diagnosis : Empyema pleurae.

Age of mother unknown; no vitamin $B_{1}$ administered to her.

\begin{tabular}{|c|c|c|c|c|c|}
\hline \multirow{2}{*}{ No. } & \multirow{2}{*}{ Date } & \multicolumn{2}{|c|}{ A. R. } & \multicolumn{2}{|c|}{ I. N. } \\
\hline & & R. & L. & R. & L. \\
\hline $\begin{array}{l}1 \\
2 \\
3 \\
4 \\
5 \\
6 \\
7\end{array}$ & $\begin{array}{r}\text { 11. IV } \\
23 . " n \\
30 . \\
7 . \\
14 . \\
21 . " \\
28 . "\end{array}$ & $\begin{array}{l}1 \text { ( (H) } \\
1 \text { (H) } \\
1 \text { (H) } \\
1 \text { (H) } \\
1 \text { (H) } \\
1 \text { (H) } \\
1 \text { (H) }\end{array}$ & $\begin{array}{ll}7 & (+) \\
1 & (H) \\
8 & (+) \\
1 & (H) \\
2 & (H) \\
1 & (H) \\
1 & (H)\end{array}$ & $\begin{array}{l}49.0 \\
50.2 \\
47.8 \\
51.7 \\
47.3 \\
53.7\end{array}$ & $\begin{array}{l}54.1 \\
45.4 \\
53.4 \\
52.1 \\
53.4 \\
53.4 \\
51.2\end{array}$ \\
\hline
\end{tabular}

2) Y. Moriwaki, Tohoku J. Exp. Med., 1944, 47, 34.

* Intermediate reaction means such an intensity of A r a k a w a's reaction which lies between Arakawa-positive milk and completely or almost completely Arakawa-negative milk. Intermediate reaction is also a clinically negative A ra ka wa's reaction. 
Case No. 2 (Cf. Table 2). As is shown in Table 2, A rakawa's reaction of this case was of an intermediate reaction* (or a clinically negative reaction). Neither a variation of the intensity of Arakawa's reaction nor the change of the iodine number of milk fat were observed. The iodine number was almost constant and the difference of 1-2 in number is negligible, only the time of observation was short.

TABLE II.

Case No. 2. S.Y. female, aged 4 months. Diagnosis: Bronchopneumonia. Age of mother unknown; no vitamin $B_{1}$ was administered to the mother.

\begin{tabular}{c|c|c|c|c|c}
\hline \multirow{2}{*}{ No. } & \multirow{2}{*}{ Date } & \multicolumn{2}{|c|}{ A. R. } & \multicolumn{2}{c}{ I. N. } \\
\cline { 2 - 6 } & & R. & L. & R. & L. \\
\hline 1 & $13 . \mathrm{V}$ & $7( \pm)$ & $7( \pm)$ & 66.3 & 65.1 \\
2 & 18. & $6( \pm)$ & $10( \pm)$ & 64.7 & 65.5 \\
3 & 21. & $9(+)$ & $11(+)$ & 65.0 & 66.9
\end{tabular}

Case No. 3 (Cf. Table 3). A rakaw a's reaction was of an intermediate reaction. In this case too, neither a large variation of A rakawa's reaction nor a fluctuation of the iodine number were observed.

From these three cases, we learn that the daily variation of the iodine number of milk fat is small, at least as far as Arakawa's reaction does not change its intensity.

TABLE III.

Case No. 3. M.F., male, aged 2 months.

Diagnosis : Lymphadenitis submaxillaris et hypogalactia.

Age of mother 30 years; no vitamin $B_{1}$ was administered to the mother.

\begin{tabular}{|c|c|c|c|c|c|}
\hline \multirow{2}{*}{ No. } & \multirow{2}{*}{ Date } & \multicolumn{2}{|c|}{ A. R. } & \multicolumn{2}{|c|}{ I. N. } \\
\hline & & R. & L. & R. & L. \\
\hline $\begin{array}{l}1 \\
2 \\
3 \\
4 \\
5\end{array}$ & $\begin{array}{l}\text { 22. IV } \\
23 . " \\
24 . " \\
25 . " \\
26 . "\end{array}$ & $\begin{array}{ll}1 & ( \pm) \\
3 & ( \pm) \\
3 & ( \pm) \\
5 & ( \pm) \\
4 & ( \pm)\end{array}$ & $\begin{array}{ll}1 & (+) \\
1 & (+) \\
1 & (+) \\
5 & (+) \\
2 & (+)\end{array}$ & $\begin{array}{l}67.6 \\
68.5 \\
66.7 \\
67.3 \\
65.9\end{array}$ & $\begin{array}{l}\overline{64.3} \\
65.1 \\
65.8 \\
66.3\end{array}$ \\
\hline
\end{tabular}

Case No. 4 (Cf. Table 4). This case was a late milk, the age of infant was already as old as 14 months, but Arakawa's reaction showed mostly a strong reaction. The iodine number of milk fat was almost that of normal case. That, even in late milk, if A rakawa's reaction is positive, the iodine number keeps a normal value, is what has already been reported in a preceding paper $^{1)}$ of mine. As the age of infant was old, the mother had had already several menstruations. Interested in the influence of menstruation on the iodine number of milk fat, I began to estimate in this case the iodine number of milk fat from 3 days prior to the coming (expected) menstruation. But, 
the mother left our Department on 5 th day of her menstruation for her infant was completely cured, so, to my regret, I could not follow any further variation of the iodine number. But, in spite of this, I obtained a certain interesting result of which I want to report here.

\section{TABle IV.}

Case No. 4. H.O., male, aged 1 year and 2 months.

Diagnosis : Bronchopnęumonia.

Age of mother, unknown.

\begin{tabular}{|c|c|c|c|c|c|c|}
\hline \multirow{2}{*}{ No. } & \multirow{2}{*}{ Date } & \multicolumn{2}{|c|}{ A. $\mathbf{R}$. } & \multicolumn{2}{|c|}{ I. N. } & \multirow{2}{*}{ 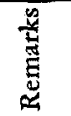 } \\
\hline & & R. & L. & R. & L. & \\
\hline $\begin{array}{l}1 \\
2 \\
3 \\
4 \\
5 \\
6 \\
7\end{array}$ & $\begin{aligned} 9 . & \mathrm{V} \\
10 . & " \\
12 . & " \\
13 . & " \\
14 . & " \\
15 . & " \\
16 . & \end{aligned}$ & $\begin{aligned} 1 & (\text { (H) } \\
1 & (H) \\
12 & (-4) \\
1 & (+) \\
1 & (H) \\
1 & (H) \\
1 & (H)\end{aligned}$ & $\begin{array}{ll}1 & (\mathrm{H}) \\
7 & (\mathrm{H}) \\
& * \\
1 & (\mathrm{H}) \\
1 & (\mathrm{H}) \\
1 & (\mathrm{H}) \\
1 & (\mathrm{H})\end{array}$ & $\begin{array}{l}56.8 \\
55.0 \\
60.0 \\
59.5 \\
59.2 \\
55.1 \\
56.6\end{array}$ & $\begin{array}{l}57.0 \\
56.4 \\
62.6 \\
59.5 \\
57.5 \\
53.1 \\
56.2\end{array}$ & 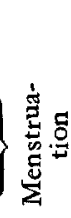 \\
\hline
\end{tabular}

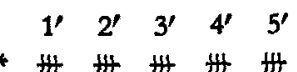

As is shown in Table 4, on the right side of the breast, Arakawa's reaction suddenly became very weakly (almost completely negative reaction) on May 12th, the day before the menstruation, and on May 13th, the first day of the menstruation it showed an intermediate reaction and after 14th, it became very strong again. On the other hand, on the left side of the breast, the weakest A rakawa's reaction was observed on May 10th, 3 days before the menstruation, and after the menstruation began, Arakawa's reaction became positive again. Owing to some other reason Arakawa's reaction of May 11th was not tested. A takawa's reaction might possibly have been the weakest on that day on the left side of the breast. At any rate, weakening of A raka wa's reaction was observed prior to the actual menstruation. While, the iodine number of milk fat was of the highest figure on the premenstrual day on both sides of the.breast and after May 15th, the 3rd day of the menstruation, it decreased to normal value of this case. Thus, both of A rakawa's reaction and the iodine number showed a premenstrual change. Such a premenstrual change of milk is very interesting as compared with the work of $\mathrm{Kokubo}^{3}$ ) in our Laboratory (Cf. 27th Hematological paper).

3) Y. Kokubo, Tohoku J. Exp. Med., 1939, 35, 243. 


\section{Variation of the iodine number of milk fat on an administration of vitamin} $B_{1}$ to nursing mothers with Arakawa-negative as well as -positive milk.

Case No. 5 (Cf. Table 5). This was also a case of late milk, the infant being 14 months old. Besides, there was even the suspicion of a new pregnancy, because she missed her recently expected menstruation. During the whole course of experiment (28 days in all, from April 23th to May 20th), Arakawa's reaction was daily tested and was always completely negative except for the first day of admission. The iodine number of milk fat was estimated as often as 9 times in all. The result is very instructive and very suggestive: At first, I began this experiment with the purpose to observe the daily variation of iodine number of completely negative milk. After I saw there was no remarkable variation of the iodine number of milk fat, I injected $1 \mathrm{mgrm}$. of vitamin $B_{1}$ only twice to the mother on May 8th and 9th. The iodine number, which had remained of a high value before the administration of the vitamin $B_{1}$, began to decrease its value very markedly from May 9th on, the next day of the administration, and the lowest value was attained on May 10ih. But, with a gradual fading of the $\mathrm{effect}$ of vitamin $B_{1}$, the iodine number began to increase again until at last it showed almost as high a value as before. In such a milk from a pregnant mother, we know from our daily experience with Arakawa's reaction that even a fairly large amount of vitamin $B_{1}$ will not change Arakawa-negative milk into Arakawapositive. In this case too, A rakawa's reaction remained completely negative; this may have been due to too small amount of vitamin $B_{1}$ used-2 mgrms. in all. But there was a marked variation in the iodine number in spite of such a small amount of vitamin $B_{1}$. In this case similar phenomenon

TABLE $V$.

Case No. 5. K.S., female, aged 1 year and 2 months.

Diagnosis : Empyema pleurae. Age of mother, 24 years.

\begin{tabular}{|c|c|c|c|c|c|}
\hline \multirow{2}{*}{ No. } & \multirow{2}{*}{ Date } & \multicolumn{2}{|c|}{ A. $\mathbf{R}$. } & \multicolumn{2}{|c|}{ I. N. } \\
\hline & & R. & L. & R. & L. \\
\hline $\begin{array}{l}1 \\
2 \\
3 \\
4 \\
5 \\
6 \\
7 \\
8 \\
9\end{array}$ & $\begin{aligned} 23 . & \text { IV } \\
24 . & n \\
2 . & \text { V } \\
6 . & n \\
9 . & n \\
10 . & n \\
13 . & n \\
15 . & n \\
10 . & n\end{aligned}$ & $\begin{array}{l}16(-) \\
16(-) \\
16(-) \\
16(-) \\
16(-) \\
16(-) \\
16(-) \\
16(-) \\
16(-)\end{array}$ & $\begin{array}{l}14(-) \\
16(-) \\
16(-) \\
16(-) \\
16(-) \\
16(-) \\
16(-) \\
16(-) \\
16(-)\end{array}$ & $\begin{array}{l}77.5 \\
68.4 \\
69.3 \\
68.4 \\
52.1 \\
41.1 \\
51.6 \\
59.5 \\
62.5\end{array}$ & $\begin{array}{l}63.7 \\
63.7 \\
62.1 \\
62.2 \\
48.8 \\
43.3 \\
54.8 \\
58.8 \\
64.7\end{array}$ \\
\hline
\end{tabular}

* $1 \mathrm{mgrm}$. of vitamin B were injected to the mother only twice, once on $8 . \mathrm{V}$. and the: other time on $9 . \mathrm{V}$. 
was observed also in the uric acid content of the mother's urine. Yamagishi, one of the members of our Laboratory, told me that he saw, on the administration of vitamin $B_{1}$, a marked decrease of uric acid, which is, according to him, generally high in amount in the urine of mothers with negative Arakawa's reaction, and that, with the fading of the effect of the vitamin, uric acid content of her urine again began to increase.

Case No. 6 (Cf. Table 6). As is shown by Table 6, vitamin $B_{1}$ was administered to the mother from the next day of admission. Total amount of vitamin $B_{1}$ was 17 mgrms. during 9 days. Arakawa's reaction began to improve its intensity from the 3 rd day of vitamin $B_{1}$ administration and the improvement of the Arakawa reaction was slightly more remarkable on the left side of the breast than on the right side. With the improvement, the iodine number of milk fat began to decrease its value, especially remarkably on the left side.

\section{TABLE VI.}

Case No. 6. Y.H., male, aged 2 months.

Diagnosis : $\mathrm{B}_{1}$-avitaminotic dyspepsia-bronchopneumonia.

Age of mother, 30 years.

\begin{tabular}{|c|c|c|c|c|c|c|}
\hline \multirow{2}{*}{ No. } & \multirow{2}{*}{ Date } & \multicolumn{2}{|c|}{ A. R. } & \multicolumn{2}{|c|}{ I. N. } & \multirow{2}{*}{$\begin{array}{l}\text { Amount of } \\
\text { vitamin } B_{1} \\
\text { given }\end{array}$} \\
\hline & & $\mathbf{R}$ & L. & $\mathbf{R}$. & L. & \\
\hline $\begin{array}{l}1 \\
2 \\
3 \\
4 \\
5\end{array}$ & $\begin{array}{l}\text { 11. XII } \\
12 . " \\
13 . " \\
14 . " \\
15 . "\end{array}$ & $\begin{aligned} 12 & (-) \\
16 & (-) \\
16 & (-) \\
16 & (-) \\
4 & (+)\end{aligned}$ & $\begin{aligned} 12 & (-) \\
16 & (-) \\
16 & (-) \\
6 & -(-) \\
1 & ( \pm)\end{aligned}$ & $\begin{array}{l}66.9 \\
68.4 \\
65.1 \\
66.0 \\
-\end{array}$ & $\begin{array}{l}52.5 \\
57.3 \\
58.2 \\
54.3 \\
-\end{array}$ & $\begin{array}{ll}1 & \text { mgrm. } \\
1 & n \\
1 & n \\
1 & 7\end{array}$ \\
\hline $\begin{array}{r}6 \\
7 \\
8 \\
9 \\
10\end{array}$ & $\begin{array}{l}16 . " \\
17 . " \\
18 . " \\
19 . " \\
20 . "\end{array}$ & $\begin{array}{l}7(t) \\
3(t) \\
5( \pm) \\
5( \pm) \\
5( \pm)\end{array}$ & $\begin{array}{ll}3 & (+) \\
1 & (+) \\
6 & (+) \\
2 & (+t) \\
4 & (+t)\end{array}$ & $\begin{array}{l}60.3 \\
62.7 \\
58.2 \\
59.1 \\
59.3\end{array}$ & $\begin{array}{l}49.1 \\
45.6 \\
47.7 \\
44.0 \\
47.4\end{array}$ & 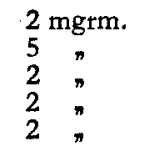 \\
\hline
\end{tabular}

Case No. 7 (Cf. Table 7). As this case was not admitted to our Department, the observation was performed only occasionaly. But an administration of vitamin $B_{1}$ was done daily to the mother from the beginning of experiment. Total amount was $17 \mathrm{mgrms}$. As is shown in Table 6, both the improvement of Arakawa's reaction and a decrease of the iodine number were distinctly observed on both sides of the breast.

Case No. 8 (Cf. Table 8). Diagnosis of this case was infantile beriberi, one of clinical manifestations of infantile $B_{1}$-avitaminosis. $1 \mathrm{mgrm}$. of vita$\min B_{1}$ and $1 / 2$ R.A.U. of yakriton, the detoxicating hormone of the liver, were daily administered to the mother from the second day (May 31th) of experiment except for Sundays (June 1st, 8th, 15th and 22nd). Total amount 
TABLE VII.

Case No. 7. J.O., male, aged 70 days.

Diagnosis : Primary infection of tuberculosis? Age of mother unknown.

\begin{tabular}{c|c|c|c|c|c}
\hline \multirow{2}{*}{ No. } & \multirow{2}{*}{ Date } & \multicolumn{3}{|c|}{ A. R. } & \multicolumn{2}{|c}{ I. N. } \\
\cline { 2 - 6 } & & R. & L. & R. & L. \\
\hline 1 & 3. II & $16(-)$ & $16(-)$ & 63.1 & 61.7 \\
2 & $6 . n$ & $4(-)$ & $11(-)$ & 63.5 & 60.9 \\
3 & $16 . " n$ & $6(-)$ & $5( \pm)$ & 59.1 & 57.2 \\
4 & $19 . " n$ & $6(+)$ & 1 (\#) & 54.3 & 49.3
\end{tabular}

From the beginning of the experiment, $1 \mathrm{mgrm}$. of vitamin $B_{1}$ was daily administered to the mother.

used of vitamin $B_{1}$ was 23 mgrms. In this case, Arakawa's reaction was not completely negative, but showed an intermediatet reaction at the beginning of the observation. On an administration of vitamin $B_{1}$ and of yakriton, A rakawa's reaction showed an inclination to improve its intensity showing some fluctuation. But curiously enough, Arakawa's reaction, which had fairly improved in intensity, became quite suddenly completely negative on June 7th. I was unable to see her for some other reason. When the mother came to me on June $10 \mathrm{ch}$. A raka wa's reaction was fairly strong again. After that day, Arakawa's reaction remained about of that strength though it became weak on June 14th. The iodine number, which was very high before vitamin $B_{1}$ was administered, tended to decrease relatively rapidly on both sides of the breast, showing a slight fluctuation. But, on June, 7th, it showed suddenly a high value, corresponding to the sudden weakening of Ara kawa's reaction. From June 10th, the iodine number began to decrease again (though it showed slightly higher figures on June 14th corresponding to the weaker reaction) until at last it showed a very low value such as 47.5 and 46.3 .

Now what was the cause of the sudden weakening of A rakawa's reaction on June 7 th and the sudden re-elevation of the iodine number? By asking her, I knew that the mother had abdominal pain and diarrhoea on that particular day. Though I could not ascribe the sudden change to a definite cause, I believe it is very interesting that June 7 th, the day of sudden weakening of Arakawa's reaction, was the 28th day after the delivery. It is not without a good reason to presume that the sudden weakening of A rakawa's reaction was due to an occult menstruation. Such a case of occult menstruation was reported by $S$ at o and Is o n $o^{4) *}$ from our Laboratory

4) Sh. S at o and S. I s o n o, Tohoku J. Exp. Med., 1939, 35, 325.

* There are also several reports on the existence of such an occult menstruation in the literature. See later (p. 381). 
who saw a periodic occurrence of methyl glyoxal like substance in human milk and a periodic weakening of Arakawa's reaction in menstrual period, occult or manifest.

\section{TABLE VIII.}

Case No. 8. M.S., male, aged 17 days. Diagnosis : Infantile beriberi. Age of mother 24 years.

\begin{tabular}{|c|c|c|c|c|c|}
\hline \multirow{2}{*}{ No. } & \multirow{2}{*}{ Date } & \multicolumn{2}{|c|}{ A. R. } & \multicolumn{2}{|c|}{ I. N. } \\
\hline & & R. & L. & R. & L. \\
\hline $\begin{array}{l}1 \\
2 \\
3 \\
4 \\
5\end{array}$ & $\begin{array}{l}\text { 30. V } \\
\text { 31. }{ }^{*} \\
\text { 2. VI } \\
\text { 3. } \\
\text { 4. " }\end{array}$ & $\begin{array}{ll}4 & (+) \\
3 & (+) \\
4 & (+) \\
2 & (+) \\
1 & (+)\end{array}$ & $\begin{array}{l}4(-) \\
4(-) \\
6( \pm) \\
6(+) \\
\ddagger\end{array}$ & $\begin{array}{l}85.7 \\
81.1 \\
64.5 \\
67.2 \\
58.8\end{array}$ & $\begin{array}{l}71.2 \\
68.1 \\
61.1 \\
77.7 \\
56.7\end{array}$ \\
\hline $\begin{array}{r}6 \\
7 \\
8 \\
9 \\
10 \\
11\end{array}$ & $\begin{aligned} \text { 5. } & n \\
\text { 7. } & n \dagger \\
11 . & " \\
14 . & " \\
25 . & n\end{aligned}$ & $\begin{array}{r}166^{\S} \\
2(-) \\
1(+) \\
10(+) \\
1(+)\end{array}$ & $\begin{aligned} 16 & \$ \\
2 & (-) \\
3 & (+) \\
3 & (-) \\
1 & (+)\end{aligned}$ & $\begin{array}{l}65.4 \\
72.3 \\
58.2 \\
57.3 \\
60.1 \\
47.5\end{array}$ & $\begin{array}{l}57.5 \\
\mathbf{6 8 . 4} \\
55.7 \\
57.3 \\
58.4 \\
46.3\end{array}$ \\
\hline
\end{tabular}

* From 31. V. vitamin $B_{1}$ and 1/2 R.A.U. of yakriton daily administered to the mother.

$\dagger$ The mother complained of diarrhoea. This day (7. VI) was the 28th day after the deli very.-Probably occult menstruation!

$\ddagger \pm \pm++$ +

$\S+\#$ \# \# H

Case No. 9 (Cf. Table 9). The diagnosis of the infant was infantile beriberi. From the third day of the observation (March 7th), $1 \mathrm{mgrm}$. of vitamin $B_{1}$ was daily injected subcutaneously to the mother except for Sundays

TABLE IX.

Case No. 9. K.K., female, aged 47 days.

Diagnosis : Infantile beriberi. Age of mother, 23 years.

\begin{tabular}{|c|c|c|c|c|c|}
\hline \multirow{2}{*}{ No. } & \multirow{2}{*}{ Date } & \multicolumn{2}{|c|}{ A. R. } & \multicolumn{2}{|c|}{ I. N. } \\
\hline & & R. & L. & R. & L. \\
\hline $\begin{array}{l}1 \\
2 \\
3 \\
4 \\
5 \\
6 \\
7\end{array}$ & 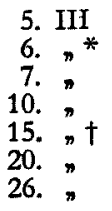 & $\begin{array}{r}12(-) \\
16(-) \\
12(-) \\
11( \pm) \\
7(+) \\
7(+) \\
2(+)\end{array}$ & 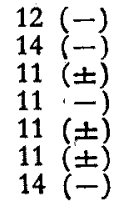 & $\begin{array}{l}64.1 \\
65.1 \\
59.2 \\
61.2 \\
54.7 \\
53.1 \\
52.9\end{array}$ & $\begin{array}{l}61.2 \\
60.0 \\
58.4 \\
59.0 \\
58.0 \\
57.7 \\
57.2\end{array}$ \\
\hline
\end{tabular}

* From 6. III, vitamin $B_{1} 1 \mathrm{mgrm}$. daily given.

$\dagger$ From 14. III, 1 R.A.U. of yakriton daily injected besides vitamin $B_{1}$. 
(March 9th, 16th and 23rd). The total amount of vitamin $B_{1}$ was 18 mgrms. Moreover, from March 14th, 1. R.A.U. of yakriton was daily administered to the mother besides vitamin B. As is shown in Table 9, Arakawa's reaction which was almost completely negative in the beginning of experiment, improved somewhat markedly on the right side, while the left side milk showed only a slight inclination to improve. The iodine number of milk fat decreased remarkably on the right side, while, on the left side, only a rather slight decrease was observed.

Case No. 10 (Cf. Table 10). From May 28th, $1 \mathrm{mgrm}$. of vitamin $B_{1}$ was daily administered to the mother. The total amount of vitamin $B_{1}$ was $15 \mathrm{mgrms}$. As is seen from Table 10, Arakawa's reaction was in this case fluctuating between positive reaction and better intermediate reaction. After vitamin $B_{1}$ was injected to the mother, Arakawa's reaction began to show more constant positive reaction.

In this case, the decrease of the iodine number of milk fat was not so remarkable as will be seen from Table 10 . The iodine number of this case was higher than the average iodine number of Arakawa-positive milk. In a preceding paper ${ }^{\text {1) }}$ (Cf. 180th Report of the Peroxidase Reaction) I found that the average iodine number of Arakawa-positive milk was 51.8, the maximum and the minimum being 70.6 and 35.4 respectively. Hence, the iodine number of this case such as 61.8 or 63.3 can still be considered as a normal value for this mother. I doubt if I could further have expected a further decrease in this case even if $I$ had fortified $B_{1}$ administration.

Table $\mathrm{X}$.

Case No. 10. S.H., male, aged 8 months.

Diagnosis : Dysepsia.

Age of mother, 28 years.

\begin{tabular}{|c|c|c|c|c|c|}
\hline \multirow{2}{*}{ No. } & \multirow{2}{*}{ Date } & \multicolumn{2}{|c|}{ A. R. } & \multicolumn{2}{|c|}{ I. N. } \\
\hline & & R. & L. & R. & L. \\
\hline $\begin{array}{l}1 \\
2 \\
3 \\
4 \\
5\end{array}$ & $\begin{array}{l}\text { 19. V } \\
21 . " n \\
24 . " \text { " } \\
27 . " \text { " * } \\
31 . \text { " }\end{array}$ & $\begin{array}{ll}4 & (+) \\
3 & ( \pm) \\
1 & (H) \\
1 & (+) \\
1 & (+)\end{array}$ & $\begin{array}{l}4(+) \\
1(t) \\
1(t) \\
1(t) \\
1(t)\end{array}$ & $\begin{array}{l}65.5 \\
63.3 \\
65.4 \\
62.3 \\
65.3\end{array}$ & $\begin{array}{l}64.2 \\
63.6 \\
69.8 \\
67.8\end{array}$ \\
\hline $\begin{array}{l}6 \\
7 \\
8 \\
9\end{array}$ & $\begin{aligned} & \text { 4. VI } \\
& 9 . " \\
& 10 . " \\
& 11 . "\end{aligned}$ & $\begin{array}{ll}1 & (+) \\
2 & (H) \\
1 & (H) \\
1 & (H)\end{array}$ & $\begin{array}{ll}1 & (+) \\
1 & (H) \\
1 & (H) \\
1 & (H)\end{array}$ & $\begin{array}{l}62.1 \\
60.2 \\
64.7 \\
61.8\end{array}$ & $\begin{array}{l}64.0 \\
62.3 \\
60.9 \\
63.3\end{array}$ \\
\hline
\end{tabular}

* From 28 . V. 1 mgrm. of vitamin $B_{1}$ daily administered to the mother. 


\section{Animal experiment (preliminary report).}

I will here give an animal experiment as a preliminary report. The experiment was done with only two rabbits, as these were only available pregnant animals for the experiment in our Laboratory at the time of experiment.

\section{Method of Animal Experiment.}

Two pregnant rabbits were exclusively fed on "tofukara"* before the delivery. After the deliver, one rabbit was fed on autoclaved tofukara $\left(120^{\circ} \mathrm{C}, 2\right.$ hours, $2 \mathrm{k} . \mathrm{grms}$. per $\left.\mathrm{cm}^{2}\right)$ and the other (control animal) was fed on the same diet plus $1 \mathrm{grm}$. of Ebios.t

As the amount of rabbit's milk was very small, milk was expressed from several glands, and such milk samples were mixed. Milk was tested with A raka wa's reaction and also used for the iodine number determination. As the composition of rabbit's milk differs from that of human milk (for instance, rabbit's milk is very high in fat content such as $10-20 \%$ ), the blue colour produced by A rakaw a reagents differs from that of human milk. It should be noted that in the present report the signs $(++,+, \pm,-)$ denote the intensity of Arakawa's reaction of rabbit's milk, but that the reaction was different from that of human milk in intensity and in shade of colour.

Method of the iodine number determination: My own micro method ${ }^{2}$ was used. Only the amount of ammonia was doubled.

\section{Result.}

The result of experiment is shown in Table 11 and Fig. 1.

Fig. 1. Showing curves of variation of the iodine number of fat in rabbit's. milk.
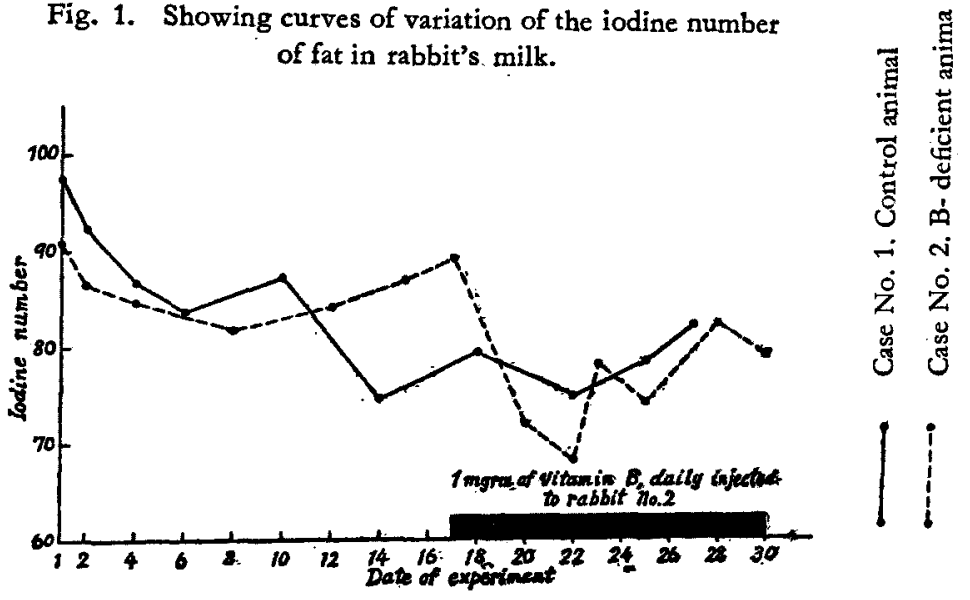

* Tofukara: "Tofu" is a food made from soy beans, a kind of bean curd, and "Kara" is the refuse left over the beans; this is swollen in water, ground and pressed.

$t$ Preparation of beer yeast. 
1. Rabbit No. 1 (control).

As is seen from Table 11, Arakawa's reaction was very weak at the beginning of the experiment (weaker than that of Rabbit No. 2 in the same period), but then gradually improved in the intensity. But again it became weaker as lactation period draws near the end. The iodine number of milk fat, which was very high at the beginning of the observation, began to decrease with the improvement of Arakawa's reaction. But in the last stage of the observation, it became higher again corresponding to the weakening of Arakawa's reaction. Fat content of milk showed almost similar inclination. During the whole course of experiment, milk secretion was somewhat poorer than in Rabbit No. 2.

2. Rabbit No. 2 (fed on $B_{1}$-avitaminotic diet after the delivery).

Arakawa's reaction of the milk improved temporarily, but from the 14th day of observation, began to become worse again until it showed a very weak reaction such as $(--- \pm \pm \pm)$ on the 18th day. Moreover, appetite also became poorer. So, from the 17 th day on, $1 \mathrm{mgrm}$. of vitamin $\mathrm{B}_{1}$ was daily injected to the animal. Arakawa's reaction began to improve again and reached the strongest intensity on the $22 \mathrm{nd}$ day of experiment (April 9th). But after a while, it began to become worse as the end of lactation came near. The iodine number, which showed a tendency to decrease at the beginning of experiment, began to increase with the weakening of A rakawa's reaction. But after vitamin $B_{1}$ was injected, the iodine number sank remarkably. The lowest value (68.2) was observed on April 9th (the 22 nd day of observation). In the terminal stage of observation, the iodine number again increased corresponding to the weakening cf. Arakawa's reaction toward the terminal stage of lactation. Fat content of milk showed almost a similar variation, though somewhat irregularily. Though the number of animals used in this preliminary report was very $f c w$, it will show a certain effect of vitamin $B_{1}$ on the iodine number of rabbit's milk fat.

\section{Comment.}

From the result, in Cases No. 1, No. 2 and No. 3, it is evident that daily variation of the iodine number of milk fat is small, at least as far as A ra ka wa's reaction keeps constant intensity. This result is in the same sense as Engel's ${ }^{5}$ report which is published already in 19,05. According to him, daily variation of the iodine number of milk fat was small, provided nursing women take ordinary mixed diet, though there is a certain individual variation of the iodine number.

5) St. Enge l, Hoppe-Seyer's Zeitschr. physiol. Chem., 1905, 44, 353. 
From the result obtained in Cases No. 5, No! 6, No. 7, No. 8 and No.9, it is distinctly shown that on an administration of vitamin $B_{1}$ to mothers with Arakawa-negative milk, Arakawa's reaction becomes much stronger in the intensity (which fact has repeatedly been shown from this Laboratory) and that, as the reaction improves, the increased iodine number of milk fat decreases to a normal value. But, as in Case No.10, if vitamin $B_{1}$ is administered to a mother with Arakawa-positive milk (or almost positive milk), there is almost no significant variation of the iodine number of milk fat.

Very interesting was Case No. 5. There was the suspicion of a new pregnancy in this case. Araka wa's reaction of the mother's milk was always completely negative during the whole course of the experiment. 'Yamagishi and Sato $^{6)}$ of our Laboratory showed that a great majority of human milk of nursing women in new pregnancy was negative to A rakaw a's reactionand that completely or almost completely negative. They further stated that even a large amount of vitamin $B_{1}$ would fail to make such a milk Arakawa-positive. In Case No. 5, $1 \mathrm{mgrm}$. of vitamin $B_{1}$ was administered only twice to the mother and such a rather small amount of the vitamin was not of course expected to improve Arakawa's reaction to any extent, especially as this was a case of pregnancy. At any rate it remained obstinately completely negative. But there was a great variation in the iodine number of milk fat (as well as in uric acid content of urine-according to Yamagishi). As soon as vitamin $B_{1}$ was administered to the mother, the iodine number of milk fat decreased markedly. And with the fading of the $\epsilon$ ffect of viamin $B_{1}$, the iodine number increased again. On the other hand, it is well known that in pregnancy, which is a physiological condition, women will be apt to become $B$-avitaminotic. From this case we see the effect of vitamin $B_{1}$ to decrease an increased iodine number of milk fat of Arakawanegative mothers, and that there is a close relation between fat metabolism of mammary gland and $\mathrm{B}_{1}$-deficiency. Furthermore, this observation will serve as another evidence from the viewpoint of iodine number that pregnancy causes a $\mathrm{B}_{1}$-avitaminotic state in the body of woman.

As to the influence of menstruation on Arakawa's reaction and the iodine number of milk fat, there are two interesting cases in my experiment, i.e. Case No. 4 and Case No. 8. Case No. 4 was a case of manifest menstruation. In this case, a premenstrual weakening of A rakaw a's reaction and a premenstrual elevation of the iodine number of milk fat were observed. $\mathrm{Kokubo} \mathrm{o}^{3}$ saw a premenstrual variation of blood picture, and Is ono and Sato ${ }^{4}$ reported that vitamin $C$ like substance increased from premenstrual

6) M. Yamagis h i and Sh. Sa țo, Tohoku J. Exp. Med., 1940, 37, 373. 
period to menstrual period and that methyl glyoxal like substance increased in menstrual period with a weakening of Arakawa's reaction, in occult as well as in manifest menstruation. Analogous processes in organism which were observed from premenstrual to menstrual period, were reported also by Szarka and WaIdbiauer ${ }^{7)}$, Mori ${ }^{8)}$, Tsutsumi ${ }^{\text {() }}$ and Kita ${ }^{10)}$-Szarka and $\mathrm{Waldbauer}^{7)}$ saw an acidosis from premenstrual to menstrual period. Mori ${ }^{8)}$ observed an increasing blood chlorin from premenstrual time to the middle of the menstrual period. Tsutsumig) reported an increase of ammonia in urine in the premenstrual period, according to $\mathrm{Kita}^{10)}$, catalase content in blood and basal metabolism rose parallel from the end of premenstrual time to the beginning of the menstrual period, and went down again in the latter half of it.

Case No. 8 is a case of an occult menstruation. Arakawa's reaction of mother's milk in this case became completely negative quite suddenly on June 7th. Of course, there is no direct proof to demonstrate that this was an occult menstruation. But on that day the mother complained of abdominal pain and had diarrhoea, and moreover the day corresponded to the 28 th day after the delivery. If we take for granted that delivery is a disguised menstruation, and presume that her sexual cycle was of 28 days type, it is highly probable that this was an occult menstruation. The existence of such an occult form of menstruation is what has already been pointed out by

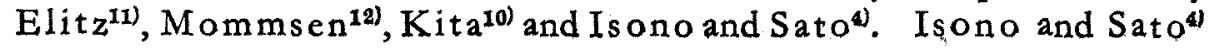
concluded as follows :- "A lactating mother can show a periodic weakening of A rakawa's reaction with about one month cycle. This is the result of a sudden increase of a methyl glyoxal like substance in her milk. And it is due to the abnormal carbohydrate metabolism at the time of menstruation occult or manifest."

In the present case (Case No. 8), the iodine number became suddenly higher corresponding to the sudden weakening of Arakawa's reaction on June 7 th which presumed to be the day of occult menstruation. In this case also, I suppose a marked increase of methyl glyoxal like substance in her milk though the actual determination was not performed.

Thus, in these two different cases of menstruation, occult and manifest, I saw a distinct elevation of the iodine number of milk fat. I reported in

7) A. Szarka and O. Wald ba uer, Klin. Wschr., 1927. 6, 599.

8) S. Mori, Shakai Igaku Zassi, 1928, No. 503, 23.

9) K. Tsutsumi, Nippon Fujinkagakkai Zassi, 1929, 24, No. 5778.

10) H. Kita, Aichi Igakkai Zassi, 1931, 38, No. 7, 1621.

11) E. Elitz, Jahrb. f. Kinderhk., 1932, 136, 82.

12) H. Momms un, Münch. med. Wsehr., 1934, 1934, 81, 1458. 
the preceding papers ${ }^{113)}$ that Arakawa-negative milk was high in fat content and that the iodine number of milk fat was high in fat-rich milk. On the other hand, Baginsky ${ }^{14}$, Bendi ${ }^{15)}$, Schlichter ${ }^{16)}$, Monti ${ }^{17)}$ and others stated that human milk in menstrual period contained ticher amount of fat. Thus it will be very natural to conclude that the iodine number of milk fat in menstrual period is high.

As to the animal experiment, I may mention it here only as a preliminary Ieport. But the results I obtained in this animal experiment were all in the sense of what I experienced in the clinical part of this treatise. Fat content of rabbit's milk was very high $(10-20 \%)$ and the iodine number of rabbit's milk fat was also very high. The maximal iodine number was 97.8 which suggest the presence of fair amount of linolic acid or lower unsaturated fatty acids (with $C_{x}$ below $C_{18}$ ) or the presence of highly unsaturated fatty acids.

As above mentioned, I saw that the daily variation of the iodine number of fat in the milks of the same groups of different Arakawa's reaction was as a rule small, as far as the intensity of A rakawa's reaction is constant. Besides, there was no remarkable change in the iodine number of Arakawa-positive (or almost positive) milk on an administration of vitamin $B_{1}$ to the mother. Whereas, in the case of Arakawa-negative milk, it is distinctly shown that the iodine number, which was high in value, decreased to normal value on an administration of vitamin $B_{1}$ to the mother, Arakawa's reaction showing an improvement thereby. Hence, it is evident that the high iodine number of Arakawa-negative milk fat was caused by $B_{1}$-deficiency of a nursing mother. Thus from the view point of the iodine number of human milk fat, we can say that Arakawa-negative milk is a milk from a B -avitaminotic body. And milk which is high in the iodine number of milk fat is generally a "bad" milk.

\section{Summary.}

1. Daily variation of the iodine number of milk fat is small as far as the intensity of Arakawa's reaction remains constant.

2. No remarkable change of the iodine number of milk fat was observed on an administration of vitamin $B_{1}$ to the lactating mother with Arakawapositive milk.

3. It is distinctly shown that the iodine number, which showed pre-

13) Y. Moriwaki, Tohoku J. Exp. Med., 176th Report of the Peroxidase Reaction.

13) A. Baginsky, Lehrbuch der Kinderkrankheiten, 8th edit., 1905 Leipzig, 37.

15) B. Bend ix, Lehrbuch der Kinderheilkunde, 7th edit., 1916 Berlin and Vienna, 253.

16) F. Schlichter, Wien. klin. Wschr., 1889, 2, 1004 and 1890, 3, 88.

17) A. Monti, Kinderheilkunde, 1899 Berlin and Vienna, Vol. I, 40. 
viously a high value, decreased to a normal value on an administration of vitamin $B_{1}$ to the mother with Arakawa-negative milk.

4. Milk in menstruation showed a high iodine number corresponding to sudden weakening of A rakawa's reaction.

5. In a case of milk from a pregnant mother, a comparatively small amount of vitamin $B_{1}$ showed a remarkable influence on the iodine number of milk fat, while Arakawa's reaction remained completely negative as it was before.

6. In a preliminary animal experiment, I saw a gradual elevation of the iodine number of fat in the milk secreted from a rabbit which was fed on $B$-avitaminotic diet. And on an administration of vitamin $B_{1}$, the iodine number decreased relatively rapidly. Fat content of rabbit's milk varied from about $10 \%$ to about $20 \%$, and the iodine number fluctuated from 68.2 to 97.8 .

7. High iodine number of milk fat in Arakawa-negative cases is generally caused by $B_{1}$-deficiency of a lactating mother.

8. Arakawa-negative milk is milk from a $\mathrm{B}_{1}$-avitaminotic body and is as a rule a "bad" milk.

\section{Conclusions.}

In a preceding paper of mine, I have shown that iodine number of milk fat of Arakawa-negative mothers is generally higher than that of Arakawapositive ones. In the present paper it was shown that an administration of vitaim $B_{1}$ caused the high iodine number in Arakawa-negative mothers to become lower. Besides it was preliminarily shown in animal experiment

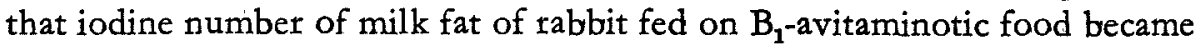
higher and that the high iodine number in $\mathrm{B}_{1}$ avitaminotic rabbit went down to a low value on an administration of vitamin $B_{\mathbf{1}}$.

It is thus shown from the view point of quality of milk fat that human milk negative to A raka wa's reaction is milk from a B-avitaminotic body. 